\title{
ФИНАНСОВО-ЭКОНОМИЧЕСКИЕ ПРИЧИНЫ ПОЛИТИЧЕСКОГО КРИЗИСА НА УКРАИНЕ. ВЗГЛЯД ЧЕРЕЗ ПРИЗМУ АНАЛИЗА БАНКОВСКОЙ СИСТЕМЫ СТРАНЫ
}

\begin{abstract}
Аннотация: На рубеже 2013-2014 г. на Украине началась волна протестов, вызванная желанием социальноэкономических перемен внутри страны, направленная, главным образом, против правящей элиты. Общество оказалось расколотым на два лагеря: один из них придерживался направления интеграции с Евросоюзом, другой - выступал за более тесное сотрудничество с Россией. Результатом противостояния на Украине стало свержение действующей власти во главе с президентом и Правительством. Финансовое положение Украины в этой связи резко ухудшилось, усилились инфляционные ожидания. Обострившийся внутриполитический кризис перерос в серьёзное внешнеполитическое противостояние, в которое была вовлечена Россия как важнейший геополитический партнёр Украины. В настоящей статье проведён обзор и анализ некоторых факторов развития фринансовой сферы и банковской системы Украины. Проведён обзор и анализ деятельности Национального Банка Украины, а также банков второго уровня. Определены направления деятельности банков, их территориальная принадлежность. Автором была предпринята попытка связать динамику изучаемых факторов, в частности, объёмов и динамики кредитных операций и операций с ценными бумагами, с происходящими негативными политическими событиями.
\end{abstract}

Ключевые слова: международные отношения, внешняя политика, Россия, Украина, политическая нестабильность, дипломатия, экономика, финансы, безопасность, ценности.

Если предположить, что экономика государства - это сложный механизм, то деньги и кредит - это топливо и масло для него. Банки, аккумулирующие деньги, выполняют в этой системе важнейшую функцию источников энергии.

Современная экономика не способна развиваться без развитой, отлаженной банковской системы.

Автор.

Политический кризис на Украине приковал внимание всего мира. Ситуация то накаляется, то немного успокаивается. Вместе с тем, понятно, что до разрешения создавшегося положения необходимо пройти непростой, весьма долгий путь. Решение политического конфликта на Украине сопряжено с решением важных экономических задач. Ведь стабилизация политической ситуации без решения вопросов, которые стоят в настоящий момент перед экономикой исследуемого государства, по мнению автора, не является возможной. Весьма важным в этой связи представляется рассмотрение экономического развития Украины с точки зрения анализа банковского сектора экономики, рассмотреть явления, происходящие в указанной сфере до осени 2013 г.
С целью выявления причин политического кризиса проведён анализ развития банковской сферы Украины.

Итак, банковская система Украины представлена Национальным банком Украины (НБУ) и системой коммерческих банков.

Рассмотрим в отдельности деятельность элементов банковской системы Украины.

Итак, функционирование НБУ определяется и регламентируется положениями Конституции Украины (ст. 85 (п. 18, 19); 99; 100; 106 (п. 12)); Законом Украины «О Национальном банке Украины»; Законом Украины «О банках и банковской деятельности».

В соответствие с Законом Украины «О Национальном банке Украины», НБУ выполняет функции:

- центрального банка Украины, являющегося особым центральным органом государственного управления;

- монопольно осуществляет эмиссию национальной валюты, организует её обращение;

- $\quad$ является кредитором последней инстанции для банков и организует систему рефинансирования;

- $\quad$ устанавливает систему, порядок, форму платежей, в том числе, между банками; устанавлива- 
ет для банков правила проведения банковских операций;

- осуществляет банковское регулирование и надзор;

- осуществляет валютное регулирование, определяет порядок осуществления операций в иностранной валюте, организует и осуществляет валютный контроль над банками и финансовыми учреждениями, которые получили лицензию НБУ на осуществление валютных операций;

- устанавливает официальный курс гривны к иностранным валютам и обнародует его;

- устанавливает номиналы, системы защиты, платёжные признаки, дизайн денежных знаков, сохраняет их резервные фонды;

- осуществляет сохранение банковских и драгоценных металлов, камней и других ценностей;

- $\quad$ размещает золотовалютные резервы, выполняет операции с ними;

- $\quad$ устанавливает порядок определения учетной ставки и других процентных ставок по своим операциям;

- $\quad$ осуществляет лицензирование банковской деятельности и операций в предусмотренных законом случаях;

- устанавливает банкам нормативы обязательного резервирования средств.

Как видно из представленного перечня функций НБУ, данное ведомство охватывает довольно широкий круг задач, среди которых можно выделить и участие в формировании капитала и деятельности международных организаций согласно международным договорам, участниками которых является Украина, а также - согласно соглашениям между НБУ и центральными банками иностранных государств.

Следует отметить, что любое решение НБУ по вопросу денежно-кредитной политики является самодостаточным, не нуждается в утверждении каким-либо другим органом ${ }^{1}$. Таким образом, ни один из органов власти не имеет полномочий для утверждения и осуществления мер регулирования денежно-кредитной политики Украины. Вся ответственность за результаты деятельности НБУ лежит на менеджменте данного ведомства ${ }^{[2,4]}$.

Одним элементов из денежно-кредитной политики Украины до 6 февраля 2014 года был ис-

\footnotetext{
1 Конституция Украины; Закон Украины «О Национальном банке Украины»; Закон Украины «О банках и банковской деятельности».
}

кусственно поддерживаемый на определенном уровне курс национальной валюты - гривны. Так, 7 февраля курс гривны к доллару был повышен сразу на 71,5 копейки, или на 8,95\%. Пересмотр официального курса проведен впервые за полтора года ${ }^{2}$.

Это свидетельствует о том, что в условиях рыночной экономики курс национальной валюты Украины не отвечал реалиям сложившейся экономической конъюнктуры, а зависел лишь от политической воли руководства НБУ. Любой внешний или внутренний шок, по мнению автора, явно ухудиили бы позищии гривны относительно других валют - доллара, евро, российского рубля. Указанные явления, очевидно, привели бы к резкому уменьшению покупательной способности гривны.

Установлено также, что в настоящее время на сайте регулятора последняя информация о собственниках банков датируется апрелем 2012 года и во многих случаях очень устарела. Согласно законодательству, публикации подлежат имена собственников, владеющих более чем 10\% пакетов акций. Поэтому многие банки дробят пакеты акций между юридическими или физическими лицами так, чтобы никому не принадлежало более $10 \%$ акций. В результате можно скрыть имена даже номинальных собственников. Следует также отметить, что в феврале 2014 г. Национальный банк должен был опубликовать отчётность о размере золотовалютных резервов по состоянию на конец января. Указанная отчётность так и не появилась. Вместо неё появилось постановление НБУ №49 «0 мероприятиях относительно деятельности банков и проведения валютных операций». Этот документ был утвержден 6 февраля. Пристального внимания заслуживает факт того, что текст постановления опубликован не был. Согласно данному постановлению, НБУ вводит «определенные ограничения на исполнение поручений банковских клиентов в пределах остатков средств на их текущих счетах на начало операционного дня». Что это может означать? По мнению экспертов, это означает, что предприятие или физическое лицо, получившие в течение дня на банковский счет определённую сумму, не смогут списать больше, чем у них было на счету до получения этой суммы. То есть, деньги на неопределённое время «зависают» на счетах НБУ.

\footnotetext{
2 http://investments.academic.ru

http://novosti.kh.ua/
} 
Кроме того, НБУ также ввел «временные ограничения» на покупку иностранной валюты на межбанковском рынке «по отдельным операциям». По каким именно - не уточняется.

Можно предположить, что речь идет о покупке валюты для населения, которое, в свою очередь, массово переводит депозиты в гривнах в твердую валюту. То есть население скупает доллары и евро в кассах банков для того, чтобы таким образом сохранить собственные накопления.

Кроме того, было установлено, что часть валюты была куплена и обналичена в последнюю неделю января и в первую неделю февраля 2014 года. В настоящее время НБУ как регулятор занялся проверкой контрактов, на основании которых покупались доллары и евро. Было установлено, что проводились валютные операции покупки валюты по нерыночному курсу, а продажа валюты осуществлялась уже по рыночному курсу4. В этой связи ограничение на покупку-продажу иностранной валюты для населения является запоздалым решением.

На основании представленных данных, можно сделать предварительные выводы о деятельности НБУ за период с 2008 по 2014 г. Во-первых, общая политика НБУ не являлась прозрачной и соответствующей экономическим реалиям. Во-вторых, осуществление надзорной функции НБУ осуществлял в недостаточной мере и, очевидно, не проводил превентивных мер по поддержанию курса собственной политики. В-третьих, НБУ своевременно не занял позицию жёсткого регулятора. Результатом указанных последствий стали: риск резкой девальвации национальной валюты, нарушение и блокирование оборота валюты на Украине. Эти последствия чреваты катастрофическим нарушением товарооборота между Украиной и её торговыми партнёрами, а также усугублением социальной напряжённости внутри Украины, которая и без того является высокой.

Перейдём к анализу следующего элемента банковской системы Украины - коммерческим банкам. По состоянию на 2014 г. банковская система Украины насчитывает 181 банк. НБУ предложил классификацию банков Украины по объёму активов.

Результаты классификации банков по величине объёма активов представлены в таблице 1.

Территориальная принадлежность владельцев банков, представляющих систему коммерческих банков Украины, представлена в таблице 2.

\footnotetext{
4 Там же.
}

Таблица 1

Классификация банков в банковской системе по объёму активов ${ }^{5}$

\begin{tabular}{|c|c|c|c|c|}
\hline $\begin{array}{c}\text { Кате- } \\
\text { гория }\end{array}$ & $\begin{array}{c}\text { Класси- } \\
\text { фикация } \\
\text { банка }\end{array}$ & $\begin{array}{c}\text { Объём акти- } \\
\text { вов/банк, } \\
\text { млн. грн. }\end{array}$ & $\begin{array}{c}\text { Коли- } \\
\text { чество } \\
\text { банков }\end{array}$ & $\begin{array}{c}\text { Доля банков } \\
\text { в банковской } \\
\text { системе, \% }\end{array}$ \\
\hline 1 & $\begin{array}{c}\text { Крупней- } \\
\text { ший }\end{array}$ & более 20000 & 15 & 8 \\
\hline 2 & Крупный & более 5000 & 20 & 11 \\
\hline 3 & Средний & более 3000 & 22 & 12 \\
\hline 4 & $\begin{array}{c}\text { Неболь- } \\
\text { шой }\end{array}$ & менее 3000 & 120 & 69 \\
\hline & - & Всего: 1273000 & Всего: 181 & Всего: 100 \\
\hline
\end{tabular}

Таблица 2

Территориальная принадлежность владельцев коммерческих банков, действующих на Украине 6

\begin{tabular}{|c|l|c|}
\hline № & \multicolumn{1}{|c|}{$\begin{array}{c}\text { Территориальная } \\
\text { принадлежность } \\
\text { банков }\end{array}$} & $\begin{array}{c}\text { Доля активов } \\
\text { в банковской системе } \\
\text { Украины, \% }\end{array}$ \\
\hline 1 & Украина & 58 \\
\hline 2 & Россия & 11 \\
\hline 3 & Евросоюз, из которого: & 24 \\
& Австрия & 8 \\
& Франция & 6 \\
& Германия & 2 \\
& Греция & Италия \\
\hline 4 & Остальной мир & 7 \\
\hline
\end{tabular}

Как следует из представленной таблицы, структуру банковского бизнеса на Украине представляют: украинские банки с долей участия 58 \%, российские банки с долей участия $11 \%$. Банки из европейских государств представлены на Украине долей участия $24 \%$.

В структуре собственников европейских банков, действующих на Украине, представлены: Австрия - доля участия $8 \%$, Франция- $6 \%$, Германия $2 \%$, Греция-1 \%, Италия-7 \%.

Остальные государства представляют весьма небольшую часть банковской системы Украины около 7 \%. Хотелось бы особо отметить, что, согласно отчёту МВФ по экономическому развитию Украины, участие США в банковской системе Украины официально не представлено.

Как следует из представленных в таблице 3 результатов, лидерами банковского бизнеса Украины по объёму активов среди указных категорий банков по состоянию на октябрь 2013 г. являются:

\footnotetext{
5 По методике НБУ по состоянию на 2012 г.

6 По данным МВФ.
} 
Политическая стабильность / Political stability

таблица 3

Объём активов банков-флагманов банковского бизнеса Украины ${ }^{7}$

\begin{tabular}{|c|c|c|c|c|c|}
\hline № & $\begin{array}{c}\text { Название } \\
\text { банка, террито- } \\
\text { риальная при- } \\
\text { надлежность; } \\
\text { форма соб- } \\
\text { ственности }\end{array}$ & $\begin{array}{c}\text { Объём } \\
\text { активов, } \\
\text { тыс. грн. }\end{array}$ & $\begin{array}{c}\text { доле- } \\
\text { дит- } \\
\text { ного } \\
\text { порт- } \\
\text { феля, } \\
\text { \% }\end{array}$ & $\begin{array}{c}\text { Доля } \\
\text { порт- } \\
\text { феля } \\
\text { цен- } \\
\text { ных } \\
\text { бумаг, } \\
\text { \% }\end{array}$ & $\begin{array}{c}\text { Доля } \\
\text { осталь- } \\
\text { ных } \\
\text { акти- } \\
\text { вов, } \\
\%\end{array}$ \\
\hline 1 & $\begin{array}{c}\text { «риватбанк» } \\
\text { Украина/ } \\
\text { Частный }\end{array}$ & 202551282 & 63,7 & 0,2 & 36,1 \\
\hline 2 & $\begin{array}{c}\text { "Ощадбанк» } \\
\text { Украина/Госу- } \\
\text { дарственный }\end{array}$ & 92319845 & 56,5 & 25,6 & 17,8 \\
\hline 3 & $\begin{array}{c}\text { «Райффайзен- } \\
\text { банк Аваль» } \\
\text { Австрия/ } \\
\text { Частный }\end{array}$ & 44803823 & 58,8 & 11,8 & 29,3 \\
\hline 4 & $\begin{array}{c}\text { «Проминвест- } \\
\text { банк» } \\
\text { Россия/ } \\
\text { Государственный }\end{array}$ & 40236687 & 69,8 & 8,4 & 21,9 \\
\hline
\end{tabular}

частный украинский «Приватбанк» с объёмом активов 202551282 тыс. грн.; государственный украинский «Ощадбанк» с объёмом активов 92 319845 тыс. грн. Среди европейских банков, присутствующих на Украине лидирующие позиции занимает «Райффайзен Банк Аваль» с объёмом активов 44803823 тыс. грн. Российские банки на Украине возглавляет «Проминвестбанк» (группа ВЭБ) с объёмом активов 40236687 млн. грн. Из указанной группы, как видно из представленной таблицы, по объёму активов лидирует частный украинский банк.

Анализ доли кредитного портфеля рассматриваемых банков показывает, что российский государственный банк лидирует по данному критерию, опережая остальные кредитные организации примерно на $10 \%$.

Анализ доли портфеля ценных бумаг исследуемых банков показывает, что лидером по данному критерию является украинский банк с государственным участием. Наименьшие доли портфелей ценных бумаг у российского банка с государственным участием - около 8 \% и у частного украинского банка - около $0,2 \%$.

Таким образом, во-первых, можно сделать предположение, что в рассмотренной категории банк с российским государственным капиталом ориентирован, в основном, на кредитную деятель-

7 По данным сайта http://forinsurer.com/ на октябрь 2013 г. ность. Это означает, что в период внешних и внутренних финансовых шоков, указанный банк в большей степени подвержен кредитным рискам.

Во-вторых, наибольшая доля портфеля ценных бумаг принадлежит украинскому банку с государственным участием. Это может означать, что в период внешних и внутренних финансовых шоков данный банк взял на себя риск уменьшения стоимости ценных бумаг.

По мнению автора, важность подобного предположения обусловлена следующим фактором. По сообщениям СМИ, правительственные бумаги составляют 70\% общего банковского портgеля. По мнению, Украинского кредитно-банковского союза, правительство Украины слишком увлеклось стимулированием банков к приобретению облигаций внутреннего государственного займа (ОГВЗ). «Искусственное создание государством привлекательных условий покупки ОВГЗ, доходность которых более $13 \%$ в гривнах и почти 8\% в долларах, превращает банки в инструмент погашения правительственных долгов и лишает экономику кредитных ресурсов. По сравнению с началом 2008 года вложения банков в ценные бумаги увеличились в 4,5 раза, что существенно опережает прирост объемов долгосрочного кредитования субъектов хозяйствования за тот же период (лишь в 1,9 раза)», - говорится в сообщении союза.

В этой связи представляет интерес провести анализ активов некоторых крупных российских банков, представленных на Украине.

Таблица 4

Объём активов банков с российским капиталом в банковском секторе Украины ${ }^{8}$

\begin{tabular}{|c|c|c|c|c|c|}
\hline № & Банк & $\begin{array}{c}\text { Объём } \\
\text { активов, } \\
\text { тыс. грн. }\end{array}$ & $\begin{array}{c}\text { доля } \\
\text { кредит- } \\
\text { ного } \\
\text { порт- } \\
\text { феля, \% }\end{array}$ & $\begin{array}{c}\text { Доля } \\
\text { порт- } \\
\text { феля } \\
\text { ценных } \\
\text { бумаг, } \\
\text { \% }\end{array}$ & $\begin{array}{c}\text { Доля } \\
\text { осталь- } \\
\text { ных } \\
\text { акти- } \\
\text { вов, \% }\end{array}$ \\
\hline 1 & $\begin{array}{c}\text { «Промин- } \\
\text { вестбанК» } \\
\text { (группа ВЭБ) }\end{array}$ & 40236687 & 69,8 & 8,4 & 21,9 \\
\hline 2 & $\begin{array}{c}\text { «СБЕРБАНК } \\
\text { РосСии» }\end{array}$ & 33571752 & 71,0 & 11,0 & 18,0 \\
\hline 3 & «ВТБ БАНК» & 29089032 & 70,9 & 0,8 & 28,2 \\
\hline 4 & УкргазбанК & 27785125 & 69,9 & 1.1 & 29,0 \\
\hline
\end{tabular}

В представленной таблице приведены следующие российские банки: Проминвестбанк, Сбербанк России, ВТБ, Укргазбанк. По объёму активов

8 По данным сайта http://forinsurer.com/ на октябрь 2013 г. 
они, очевидно, относятся к группе крупнейших банков Украины. Лидером по объёму активов исследуемой группе является Проминвестбанк (группа ВЭБ). Анализ кредитного портфеля рассматриваемых банков показывает, что в структуре активов доля кредитов среди всех указанных в таблице банков примерно одинакова и составляет около 70 \%. Доля портфеля ценных бумаг в структуре активов исследуемых банков относительно невысока: в случае ВТБ- менее одного \%, максимальное значение она составляет в структуре активов Сбербанка России: $11 \%$.

Таким образом, ключевым аспектом деятельности российских банков на Украине является кредитная деятельность. Доля ценных бумаг в структуре активов данных банков невелика.

Следует отметить, что вследствие ухудшающейся экономической ситуации кредитная деятельность на Украине всё больше сопряжена с рисками. Так, на начало 2013 года в Укрсоцбанке портфель кредитов физических лиц составил 17,3 млрд гривен. Из них 80\% - ипотечные кредиты, номинированные в валюте. Кредиты, выданные физическим лицам с просрочкой оплаты более 360 дней, превысили 9,5 млрд. грн. С начала 2009 банку пришлось занять жёсткую позицию по отношению к заёмщикам, не соглашаясь на реструктуризацию долгов. Как говорится в финансовом отчете Укрсоцбанка за 2012 г. , ожидаемые поступления от реализации залогов составляют от $30 \%$ до 70\% их первоначальной оценки 9 .

Однако данные проблемы связаны с общим состоянием экономики Украины, носят временный характер и, очевидно, могут быть преодолены в случае улучшения экономического положения страны.

С целью экономической помощи Украине в конце 2013 г. руководством РФ было принято решение о размещении части средств российского Фонда национального благосостояния (ФНБ) в государственные ценные бумаги Украины. Руководство России неоднократно указывало, что средства ФНБ было решено «...не потратить, а разместить». Кстати, таким образом, российские банки на Украине, по мнению автора, получают возможность диверсификации деятельности.

По словам Президента РФ, «...мы средства наших резервных фондов до сих пор вкладывали в высоколиквидные бумаги американского правительства, некоторые другие активы. Но, во-первых, и там не все в порядке, если посмотреть на состоя-

\footnotetext{
9 http://forbes.ua/
}

ние американской экономики. Она поднимается,... но и там много проблем. Посмотреть только на проблему долга, одна эта проблема чего стоит. Как поведет себя ведущая резервная валюта мира, мы не знаем. Поэтому... есть риски», - объяснил глава государства. «...сегодня украинская тема интересная, с учетом нашего решения», - сказал он. Президент пояснил, что выход мировой экономики из кризиса был ключевой темой обсуждения на саммите «Большой двадцатки». На форуме были рассмотрены два направления. Первое - т.н. «американское», которое связано с мягким финансовым регулированием, с дешевыми бесплатными деньгами для экономики, второе - т.н. «европейское», суть которого заключается в бюджетной консолидации, выравнивании макроэкономических показателей.

«Для нас было непростым делом как-то совместить эти две позиции в ходе “двадцатки” в Петербурге. Мы нашли определенную формулу, где и овцы целы, и волки сыты», - сказал президент. Он объяснил, что после введения бюджетного правила была продолжена политика изъятия излишних денег из экономики, связанных с благоприятной внешнеэкономической конъюнктурой, вследствие чего образовались свободные деньги, которые было решено вложить в ценные бумаги Украины, в транспортную инфраструктуру. «Мы их не просто пускаем в экономику вообще, а на конкретные вещи, на конкретные проекты, прежде всего речь идет об инфраструктурных проектах», - отметил президент ${ }^{10}$.

Итак, решение российского руководства направлено на поддержание Украины как важнейшего стратегического партнёра России. Несмотря на неблагоприятную экономическую конъюнктуру, которая сложилась на Украине, данное решение обусловлено уверенностью в «фундаментальные, базовые, положительные конкурентные преимущества». По мнению Президента РФ, «у нас очень большой уровень кооперации. ...Поэтому для нас это и политическое, и прагматическое, и экономическое решение» ${ }^{11}$.

Вместе с тем, особого внимания заслуживает деятельность одной из американских частных инвестиционных компаний.

Рассмотрим результаты деятельности данной компании в сфере приобретения государственного долга Украины.

\footnotetext{
10 vedomosti.ru; rbc.ru

11 Там же.
} 
Политическая стабильность / Political stability

По состоянию на лето 2013 г., объём государственных облигаций Украины в портфеле активов указанной компании составил 5 млрд. долл., что составляет примерно 20 \% государственного долга страны. Финансовые власти Украины, среди которых были «...первый вице-премьер и министр финансов», посещали штаб-квартиру американской инвестиционной компании в Калифорнии, чтобы убедить её руководство в надежности вложений в украинскую экономику ${ }^{12}$.

Важно отметить, что, по состоянию на осень 2013 г., рейтинговые агентства значительно снизили кредитные рейтинги Украины. Так, Fitch понизило рейтинг Украины до уровня «В-» с негативным прогнозом; важно отметить, что инвесторы определяют данный уровень как «мусорный». Moody's в указанный период снизило рейтинг до «Саa1» с негативным прогнозом по рейтингу.

В начале 2014 года американская частная инвестиционная компания владела украинскими облигациями уже на млрд. долл. Это составило $40 \%$ государственного долга Украины.

Таким образом, американские частные инвесторы занимались агрессивной скупкой долговых обязательств Украины, несмотря на неблагоприятные прогнозы. Результатом подобной деятельности стали потери: стоимость рассматриваемых активов упала на 522 миллиона долларов. На стоимости украинских облигаций негативно сказался экономический и политический кризис в стране ${ }^{13}$. Однако представители американской инвестиционной компании отказались прокомментировать сообщения издания. Пристального внимания заслуживает следующее обстоятельство. В 2014 г. Киев должен будет вернуть кредиторам около 10 млрд. долл. По состоянию на конец сентября 2013 г. стоимость страховки от дефолта Украины резко выросла, превысив 1000 пунктов. Это означает, что вероятность отказа Киева от своих долгов инвесторы оценивали на тот момент в $10 \%$. Нарастание политического конфликта привело к тому, что в феврале 2014 г. февраля стоимость страховки от дефолта Украины составила 1225 пунктов. Это означает, что инвесторы оценили вероятность дефолта страны в $60 \%$.

В 2014 г. международные рейтинговые агентства Standard \& Poor's и Moody's далее снизили рейтинг Украины. Так, в конце января Moody's опустило рейтинг Украины с «Саa1» до «Сaa2» с негативным прогнозом. В конце февраля Standard \& Poor's снизило рейтинг страны с «СCC+» до «ССС», то есть до преддефолтного уровня с негативным прогнозом. Обязательства Украины, тем самым, продемонстрировали наихудшую динамику среди всех ценных бумаг развивающихся стран ${ }^{14}$.

Общий объем госдолга Украины, выраженный во всех валютах, составляет около 60 миллиардов долларов ${ }^{15}$. Следует особенно отметить, что более половины из этой суммы - краткосрочные долги, которые нужно будет отдать до 2017 года.

Таким образом, финансово-экономические причины политического кризиса связаны со следующими аспектами.

Во-первых, негативные процессы в экономике Украины продолжали усугубляться; постоянно увеличивался государственный долг, уменьшались международные резервы. В результате эти процессы привели к росту социальной напряженности в стране.

Во-вторых, неопределённая позиция руководства Украины и метания между западными странами и Россией, как наиболее важными кредиторами, привели к расколу внутри страны. Выбор того или иного кредитора, по мнению автора, означает для Украины выбор внешнеполитического и внешнеэкономического векторов либо в пользу западных стран (Евросоюз и США), либо в пользу России. В результате Украина ещё больше стала уходить от решения насущных экономических проблем: по состоянию на конец 2013 г., Украина подходила к рубежу выплаты части государственного долга.

Кроме того, неопределённая политика в отношении кредиторов приводит к появлению на финансовом рынке Украины игроков до определённого момента находящихся в тени, но затем занимающихся стремительной и агрессивной скупкой государственного долга страны, не считаясь с возможными потерями. Подобные действия направлены на усиление финансового влияния на страну и негативно сказываются на отношениях Украины с надёжными экономическими партнёрами, в частности, с Россией. Причём особенно важно, что российская сторона действует в отношениях с украинскими партнёрами абсолютно прозрачно, не скрывая своих намерений и предупреждая о своих экономических и финансовых действиях не только

\footnotetext{
14 http://www.ft.com/

15 http://www.ft.com/; rbc.ru; http://forinsurer.com/
} 


\section{Международные отношения / International Relations}

Украину, но и весь мир. Более того, действия России согласованы с мировым сообществом и направлены на скорейшее преодоление глобального кризиса.

В-третьих, негативная экономическая ситуация привела на Украине к тому, что доля безнадёжных кредитов увеличилась. Это явление, в свою очередь, спровоцировало убытки банков. Вследствие этого, рейтинги банков, работающих на Украине, как впрочем, и рейтинг самой страны на международной экономической арене, снизились. Понижение рейтингов банков, в свою очередь, привело к уменьшению доверия к банкам и увеличению числа банков, не справившихся с негативной экономической ситуацией. Таким образом, очевидно, создалась ситуация, напоминающая замкнутый круг: выключение банков из экономического цикла, приводящее к ещё более удручающим последствиям для экономики, дальнейшему уменьшению ресурсной базы государства и последующему увеличению государственного долга. Кроме того, в сложившихся обстоятельствах всё чаще аналитики стали предупреждать о риске инфляции. Особенно хотелось бы отметить, что быстрого выхода из сложившейся ситуации сложно предвидеть, поскольку в крайне нестабильной политической обстановке возрастают риски для кредитных ор- ганизаций, поэтому не исключено, что некоторые банки будут выходить из капиталов на Украине. Подобное явление весьма нежелательно для экономики, т.к. уход банков означает и уход ресурсов для её развития. Как, например, это произошло в случае Альфа-Банка на Украине.

В-четвёртых, выбор внешнеполитического вектора Украины затрагивает интересы России, представленной в анализируемой стране рядом крупных российских государственных банков. Общая негативная ситуация в экономике Украины сказывается и на деятельности российских кредитных организаций. Вместе с тем, по мнению автора, западные конкуренты и силы, действующие с ними совместно внутри Украины, пытаются использовать сложившуюся неразбериху в общеполитической ситуации с целью ограничения сфер экономического влияния России в анализируемом регионе. Однако замечу, что позиции российских банков с государственным участием на Украине, очевидно, сильны: указанные банки входят в группу крупнейших банков Украины, являются ведущими, долгое время действуют на её территории, обладают колоссальными ресурсами, устойчивы к внешним и внутренним экономическим шокам, являются надёжными партнёрами Украины.

\section{Библиография}

1. Конституция Украины;

2. Закон Украины “О Национальном банке Украины”;

3. Закон Украины "О банках и банковской деятельности”;

4. http://investments.academic.ru

5. http://novosti.kh.ua/

6. http://forbes.ua/

7. vedomosti.ru

8. rbc.ru

9. http://www.ft.com/

10. http://www.bloomberg.com/

11. http://www.imf.org/

12. http://forinsurer.com/

13. Гушер А.И. Кризис на Украине: геополитические и геостратегические аспекты // NB: Международные отношения. - 2014. - 4. - C. 79-89. DOI: 10.7256/2306-4226.2014.4.11605. URL: http://www.e-notabene. $\mathrm{ru} /$ wi/article_11605.html

14. Бородинов Е.Н. Причины и следствия государственного переворота на Украине // NB: Международные отношения. - 2014. - 3. - С. 36-59. DOI: 10.7256/2306-4226.2014.3.11501. URL: http://www.enotabene.ru/wi/article_11501.html

15. Манойло А.В. Вооруженный мятеж в Украине: волна цветных революций идет на Россию // NB: Международные отношения. - 2014. - 3. - C. 27-35. DOI: 10.7256/2306-4226.2014.3.11498. URL: http:// www.e-notabene.ru/wi/article_11498.html

16. Гушер А.И. Вызовы и угрозы безопасности России // NB: Международные отношения. - 2014. - 1. C. 64-75. DOI: 10.7256/2306-4226.2014.1.10748. URL: http://www.e-notabene.ru/wi/article_10748.html 


\section{Политическая стабильность / Political stability}

17. Манойло А.В. Вооруженный мятеж в Украине может стать для России последним тревожным звонком // NB: Международные отношения. - 2014. - 2. - С. 24-37. DOI: 10.7256/2306-4226.2014.2.11137. URL: http://www.e-notabene.ru/wi/article_11137.html

18. Спиридонов В.В. Экономические причины политического конфликта на Украине // NB: Международные отношения. - 2014. - 4. - C. 45-78. DOI: 10.7256/2306-4226.2014.4.11528. URL: http://www.enotabene.ru/wi/article_11528.html

19. Кучерявенко Н.П.. Согласование родовых и видовых конструкций при регулировании бюджетных доходов. // Финансовое право и управление. - 2014. - № 1. - С. 120-140. DOI: 10.7256/23100508.2014.1.9886

20. Воронова Л.К.. Новое законодательство Украины о бюджетных расходах как третьей стадии бюджетного процесса. // Финансовое право и управление. - 2014. - № 1. - С. 23-44. DOI: 10.7256/23100508.2014.1.988

\section{References}

1. Konstitutsiya Ukrainy;

2. Zakon Ukrainy "O Natsional'nom banke Ukrainy";

3. Zakon Ukrainy "O bankakh i bankovskoi deyatel'nosti";

4. http://investments.academic.ru

5. http://novosti.kh.ua/

6. http://forbes.ua/

7. vedomosti.ru

8. rbc.ru

9. http://www.ft.com/

10. http://www.bloomberg.com/

11. http://www.imf.org/

12. http://forinsurer.com/

13. Gusher A.I. Krizis na Ukraine: geopoliticheskie i geostrategicheskie aspekty // NB: Mezhdunarodnye otnosheniya. - 2014. - 4. - C. 79-89. DOI: 10.7256/2306-4226.2014.4.11605. URL: http://www.e-notabene. ru/wi/article_11605.html

14. Borodinov E.N. Prichiny i sledstviya gosudarstvennogo perevorota na Ukraine // NB: Mezhdunarodnye otnosheniya. - 2014. - 3. - C. 36-59. DOI: 10.7256/2306-4226.2014.3.11501. URL: http://www.e-notabene. $\mathrm{ru} /$ wi/article_11501.html

15. Manoilo A.V. Vooruzhennyi myatezh v Ukraine: volna tsvetnykh revolyutsii idet na Rossiyu // NB: Mezhdunarodnye otnosheniya. - 2014. - 3. - C. 27-35. DOI: 10.7256/2306-4226.2014.3.11498. URL: http:// www.e-notabene.ru/wi/article_11498.html

16. Gusher A.I. Vyzovy i ugrozy bezopasnosti Rossii // NB: Mezhdunarodnye otnosheniya. - 2014. - 1. - C. 64-75. DOI: 10.7256/2306-4226.2014.1.10748. URL: http://www.e-notabene.ru/wi/article_10748.html

17. Manoilo A.V. Vooruzhennyi myatezh v Ukraine mozhet stat' dlya Rossii poslednim trevozhnym zvonkom // NB: Mezhdunarodnye otnosheniya. - 2014. - 2. - C. 24-37. DOI: 10.7256/2306-4226.2014.2.11137. URL: http://www.e-notabene.ru/wi/article_11137.html

18. Spiridonov V.V. Ekonomicheskie prichiny politicheskogo konflikta na Ukraine // NB: Mezhdunarodnye otnosheniya. - 2014. - 4. - C. 45-78. DOI: 10.7256/2306-4226.2014.4.11528. URL: http://www.e-notabene. $\mathrm{ru} /$ wi/article_11528.html

19. Kucheryavenko N.P.. Soglasovanie rodovykh i vidovykh konstruktsii pri regulirovanii byudzhetnykh dokhodov. // Finansovoe pravo i upravlenie. - 2014. - № 1. - C. 120-140. DOI: 10.7256/2310-0508.2014.1.9886

20. Voronova L.K.. Novoe zakonodatel'stvo Ukrainy o byudzhetnykh raskhodakh kak tret'ei stadii byudzhetnogo protsessa. // Finansovoe pravo i upravlenie. - 2014. - № 1. - C. 23-44. DOI: 10.7256/2310-0508.2014.1.988 